\title{
Regional processes drive bryophyte diversity and community composition in a small oceanic island
}

\author{
D. S. G. Henriques ${ }^{1,2}$, P. A. V. Borges ${ }^{1}$ and R. Gabriel ${ }^{1}$ \\ ${ }^{1}$ CE3C - Centre for Ecology, Evolution and Environmental Changes / Azorean Biodiversity Group and Universidade \\ dos Açores - Faculdade de Ciências Agrárias e do Ambiente, 9700-042 Angra do Heroísmo, Açores, Portugal \\ 2 Corresponding author, debora.sg.henriques@uac.pt
}

Keywords: Azores, Beta diversity, Climatic variables, Disturbance, Liverworts, Mosses, Spatial scale, Substrate specificity.

\begin{abstract}
How are bryophyte alpha and beta diversities distributed across spatial scales along an elevational gradient in an oceanic island? Which mechanisms and drivers operate to shape them? Starting from a multiscale hierarchical sampling approach along an $1000 \mathrm{~m}$ elevational transect, we used additive diversity partitioning and null modeling to evaluate the contributions of the alpha and beta diversity components to overall bryophyte diversity in Terceira Island, Azores. Substrate-level diversity patterns were explored by means of the Sørensen Similarity Index and the Lloyd Index of Patchiness. Elevation-level beta diversity was decomposed into its replacement and richness differences components, with several environmental variables being evaluated as diversity predictors. Bryophyte diversity proved to be primarily due to beta diversity between elevation sites, followed by diversity among substrates. Compositional differences between neighboring sites decreased with elevation, being mainly caused by species replacement and correlating with differences in relative humidity and disturbance. At the substrate level, we found a great homogeneity in terms of species composition, coupled with a low substrate specialization rate. We conclude that, in Terceira's native vegetation patches, regional processes, such as environmental gradients associated with elevation, play a greater role in shaping bryophyte diversity than local processes. Moister and less disturbed areas at mid-high elevation harbor a richer bryoflora, consistently more similar and stable between neighbouring sites. Simultaneously, the different substrates available are somewhat ecologically redundant, supporting few specialized species, pointing to these areas providing optimal habitat conditions for bryophytes. Our findings provide a better understanding of how bryophyte diversity is generated in Terceira Island, indicating that management and conservation measures should focus on island-level approaches, aiming to protect and rehabilitate additional natural vegetation patches at different elevations, especially in the severely disturbed lowlands.
\end{abstract}

Nomenclature: Söderström et al. (2016) for liverworts and Ros et al. (2013) for mosses.

\section{Introduction}

Establishing how biological communities are assembled and why they differ are two fundamental topics in community ecology (Sutherland et al. 2013). This strenuous task involves the study of community structure at various spatial scales, as observed patterns vary according to the scale of study (Wiens 1989) and spatial resolution (e.g., Gering and Crist 2002). This crucial role of spatial scale in diversity studies was first brought to light by Whittaker (1960), when he established the concepts of alpha, beta and gamma diversity. According to his multiplicative approach, the overall diversity of a given geographic area (gamma diversity) could be calculated as the product of diversity within (alpha diversity) and among individual site communities (beta diversity) in that same area (see Whittaker et al., 2001 for a review). However, these components cannot be weighted equally when calculating the relative contributions of alpha and beta diversity to overall diversity across different spatial scales (Lande 1996, Gering et al. 2003). This problem was addressed by Lande (1996), who suggested a partition into additive instead of multiplicative components, with all diversity components being expressed in the same units in order to be directly compared. Despite some critics against the additive beta partitioning (Jost et al. 2010), especially for producing dependent alpha and beta estimates (Jost 2010), the same applies to beta multiplicative, since alpha and beta are not completely conditionally independent (Veech and Crist 2010). In fact, it has been shown that both approaches are very similar and mathematically related (Ricotta 2005). In spite of such debate, the additive partitioning of species diversity adapted to Whittaker's alpha, beta and gamma diversity concepts is now widely used (Veech et al. 2002) and considered to be a logical and statistically valid approach (Veech and Crist 2010).

Nevertheless, even though analytical tools are available and spatial scale variation has repeatedly proved to be an important factor in determining community assembly structure, many studies end up focusing only on one single scale (Williams et al. 2002). Due to the importance of spatial scale for diversity patterns, a focus shift to multi-scale studies is crucial for the development of informed and comprehensive conservation strategies in which management efforts are better allocated and, consequently, more effective (Müller and 
Goßner 2010). Such endeavors are especially important in islands, which behave as biodiversity reservoirs hosting many unique species (Paulay 1994) that are particularly vulnerable to habitat loss due to threats such as land-use change, habitat deterioration, biological invasions and climate change (Caujapé-Castells et al. 2010, Courchamp et al. 2014). Adding to their value as biodiversity repositories, oceanic islands have been increasingly used in the last 50 years as isolated, bounded and manageable models of biological communities, being considered ideal sites in which to make predictions regarding community assembly rules (Warren et al. 2015). Within these bounded ecosystems, insular floras are recognized by their ecological value, with around one quarter of all known vascular taxa being island endemics (Kreft et al. 2008). Moreover, most island ecosystems also provide good basis for the development of rich bryofloras (Miller and Whittier 1990, Sjögren 1997) making bryophytes the ideal study subjects.

When used as case studies for multiscale assembly analysis in islands, bryophyte communities proved to be shaped by sets of macroscale, mesoscale and microscale variables, some of which are highly correlated (e.g., Suren 1996, Andrew and Rodgerson 2003, Gabriel and Bates 2005). For New Zealand's South Island's aquatic bryophytes, microscale variables (such as stream slope and stability) influence bryophyte presence but not community composition, which appears to be determined by meso- and macroscale factors like water quality and land-use (Suren 1996). A joint bryophyte-invertebrate composition study in Australia and New Zealand, using a four level hierarchical sampling protocol, reported bryophyte compositional differences between biogeographical regions, mountains, elevations and withinelevation locations (Andrew and Rodgerson 2003). In the Azores, Gabriel and Bates (2005) used a three level sampling approach (sites $>$ substrates $>$ quadrats) to classify Terceira's natural forest bryophytes into eight community types and were able to identify multiscale environmental factors driving community composition: rainfall at the elevation level, $\mathrm{pH}$ at the substrate level and distance to the soil and to the canopy at the quadrat level.

Building on this knowledge, we used a five-level multiscale hierarchical sampling approach (microplots, substrates, quadrats, plots and elevations) to determine which spatial levels captured the majority of bryophyte diversity in native vegetation areas of Terceira Island, Azores. Furthermore, we correlated the compositional differences we found with explanatory environmental variables. Starting from the null hypothesis that the observed bryophyte diversity across spatial levels did not differ from that expected by random processes, we hypothesized that there would be a significant deviation between observed and expected diversity across hierarchical levels, namely at (1) the substrate level (between different substrates), owing to differences in species composition due to substrate specificity and (2) at the broadest spatial level (between elevational steps) owing to the environmental gradients associated with elevation (climatic and spatial variables).

\section{Materials and methods}

Study area

Located in the middle of the Atlantic Ocean, Terceira is one of nine volcanic islands that constitute the Azores archipelago. Extending for $402 \mathrm{~km}^{2}$ and peaking at $1021 \mathrm{~m}$ a.s.l., the island is characterized by a temperate oceanic climate, with high relative humidity, regular precipitation and strong dominant SE and NW winds (Forjaz 2004). In the lowlands, the mean temperature values oscillate between $15^{\circ} \mathrm{C}$ and $25^{\circ} \mathrm{C}$, while mean rainfall ranges from $30 \mathrm{~mm}$ in July to 130 $\mathrm{mm}$ in January. At higher elevations the weather gets cooler and moister, with a mean annual rainfall of more than 2800 $\mathrm{mm}$ and minimum and maximum temperatures of, respectively, less than $6^{\circ} \mathrm{C}$ and $13^{\circ} \mathrm{C}$ to $14^{\circ} \mathrm{C}$ (Forjaz 2004).

The island's highest point, the Santa Bárbara Volcanic Complex, is considered to be a biodiversity hotspot, enfolding some of the archipelago's best preserved and richest natural biotopes (Dias and Mendes 2007). Further down, a major part of the island's interior is occupied by a number of volcanic structures, one possible reason why human settlers chose to establish mainly along the coastal lowlands (Agostinho 1942). This selective colonization process resulted in the destruction of the native lowland vegetation to make way for pastureland, used nowadays for rotational crops and grazing dairy cattle (Silveira 2013).

Benefiting from the mild and moist climate, Terceira's bryoflora is quite rich, despite the island's small size and isolation (Gabriel and Bates 2005, Aranda 2013). It is currently known to comprise 354 taxa (species and subspecies), from which 207 are mosses, 143 are liverworts and four are hornworts (Gabriel et al. 2010, updated by Aranda et al. 2014 and Ellis et al. 2015). This richness is unevenly distributed along the island's elevational gradient, with maxima at midhigh elevations being correlated with climatic and land-use variables and greatly attributed to the habitat preferences of liverworts (Henriques et al. 2016).

\section{Sampling and identification}

A transect was projected along the western side of the island, entirely inside the limits of its Natural Park so as to contain the best preserved native vegetation areas. A total of 12 permanent plots were set up in pairs, from $40 \mathrm{~m}$ a.s.l. (Serreta lighthouse) to $1000 \mathrm{~m}$ a.s.l. (Santa Bárbara Mountain) at a $200 \mathrm{~m}$ elevational step, and sampled from 26-28 Sep 2012.

The sampling methodology followed the BRYOLAT protocol (Ah-Peng et al. 2012) adapted by Gabriel et al. 2014), a multiscale hierarchical sampling protocol for the collection of bryophytes and ferns along environmental gradients. Essentially, two plots of $10 \mathrm{~m} \times 10 \mathrm{~m}(\mathrm{P} 1$ and P2) are established, roughly 10 to $15 \mathrm{~m}$ apart, at each of the six elevation sites in Terceira Island, securing that the two plots are included in the same vegetation type and are true replicates. Each plot is then subdivided into 25 quadrats of $2 \mathrm{~m} \times 2 \mathrm{~m}$, three of which are randomly selected to be sampled. In each quadrat, 
three $50 \mathrm{~cm}^{2}$ microplots are collected from rocks, soil, humus, decomposing wood and leaves (from ferns, shrubs and trees). For trees, nine replicates of the $50 \mathrm{~cm}^{2}$ microplots are made, three up to $50 \mathrm{~cm}$ height, three from $51 \mathrm{~cm}$ to $100 \mathrm{~cm}$ and three above $100 \mathrm{~cm}$, when possible. In each microplot, bryophyte species presence/absence is recorded.

Therefore, at each elevation level, 144 microplots could potentially be collected if all microhabitats were to be available and colonized by bryophytes, resulting in a theoretical total of 864 microplots for the entire transect. In practice, 636 samples (totalizing $76 \%$ of the possible microplots) were collected and all bryophytes except four were identified to species level (3680 identifications).

\section{Environmental variables}

To complement the sampling procedure with information about the physical environment of the plots, data on some landscape variables, namely average and maximum canopy height was also gathered in loco. The canopy height variables were determined based on all the woody species present in each plot, as is further explained in Gabriel et al. (2014). A landscape disturbance index devised by Cardoso et al. (2013) was also computed in order to assess the level of anthropogenic disruption in each plot. This index takes into account the landscape configuration, ranking the disturbance of land use types in relation to an undisturbed pristine native forest, in which the values of richness and abundance of endemic species were maximal and presence of exotic species minimal. The index defines an anthropogenic disturbance gradient that varies from 0 (no disturbance at all, indicating the presence of pristine natural forests) and 100 (maximum possible disturbance, indicating a prevalence of urban/industrial uses). For each $100 \mathrm{~m} \times 100 \mathrm{~m}$ cell, the index accounts for distance-dependent effects of disturbance, double weighting the value of the focal cell compared with the adjacent ones. A cell with native forest and surrounded by mostly exotic forest will have a high disturbance score, but if exotic forest or other non-native habitats are located far away from the focal cell, then those habitats will have an almost negligible individual influence (see formula and additional details in Cardoso et al. 2013).

Climatic data were retrieved from the CIELO Model (Azevedo et al. 1999), a simulation of local insular climate based on data from a reference meteorological station. As variables, we considered the maximum temperature of the warmest month, the minimum temperature of the coldest month, the precipitation of the driest month, the precipitation of the rainiest month and the minimum and maximum relative air humidity (see Supplementary Material, Appendix S1).

\section{Data analysis}

In order to assess inventory completeness, using the smallest available sampling grain seems to produce the most precise and unbiased diversity estimations (Hortal et al. 2006). Thus, species accumulation curves were generated based on a microplot-scale richness matrix and, as only incidence data were used, first- and second-order Jackknife and Chao 2 estimators were used to estimate true species richness and the sampling effort needed to obtain reliable richness estimates. These estimates were the average of 999 randomizations and were carried out both for the entire data frame and separately for each bryophyte division (mosses and liverworts) and sampled substrate.

To test our working hypothesis, we applied additive partitioning (Lande 1996, Veech et al. 2002) of bryophyte diversity to our transect using a nested hierarchical design of five increasingly broader levels: microplots, substrates, quadrats, plots and elevations. This methodology models total diversity $(\gamma$; gamma) as a sum of the average diversities within sampling units ( $\alpha$; alpha diversity) and among sampling units ( $\beta$; beta diversity), the latter across all the scales included in the hierarchical design. In our case, the partitioning of species diversity is thus expressed as:

$$
\begin{aligned}
& \gamma=\alpha_{1 \text { (microplots) }}+\beta_{1 \text { (microplots) }}+\beta_{2 \text { (substrates) }}+\beta_{3 \text { (quadrats) }}+\beta_{4 \text { (plots) }} \\
& +\beta_{5 \text { (elevations) }}
\end{aligned}
$$

This approach allows us to disentangle the relative contributions of the alpha and beta components to overall gamma diversity and to generate a null model through a randomization procedure (in our case, using 999 random distributions) to test the statistical significance of all level-specific alpha and beta diversity values.

After determining the most significant diversity components along the Island transect, the bulk of dissimilarities at both macro- and micro-scale levels was explored. At the broadest scale, beta diversity between elevations was decomposed into its true species replacement or pure turnover and richness differences components, according to the beta diversity partition methodology proposed by Carvalho et al. (2012). In this way it is possible to determine which process is originating the dissimilarities among elevations, either the gradual substitution of species by other species (replacement) and/or the difference in species numbers between communities (richness differences). Overall beta diversity, replacement and richness differences were computed both for adjacent elevations and for all possible pairs of elevations. Obtained values were plotted against geographic distances between elevations, and correlations were tested using Mantel tests.

At the same level, all environmental variables gathered to characterize the sites were evaluated concerning their ecological significance as diversity predictors for bryophytes. Given that these organisms have high water requirements and, as such, favour mild and moist habitats, maximum rainfall and relative humidity as well as minimum temperature would not restrict their distribution. For this reason, these variables were not considered. To avoid collinearity, we checked for significantly high correlations $(r>0.9 ; \alpha=0.005)$ between the remaining six variables using the Pearson product-moment correlation coefficient. After removing three highly correlated variables, only minimum rainfall, the disturbance index and the maximum canopy height remained to be used in subsequent analysis. Jaccard dissimilarity matrices between elevations were then computed for each variable and the results 
were tested against overall beta diversity and its components using a Mantel test (Legendre and Legendre 1998) to determine if and how beta diversity correlates with each environmental variable. All the aforementioned analyses were performed using R Statistical Software version 3.3.0, namely the BAT and vegan packages.

To explore diversity patterns at the substrate level and to be able to compare them with previous studies (namely Gabriel and Bates 2005), we used both the Sørensen Similarity Index (SSI) and the Lloyd Index of Patchiness (Lloyd 1967). The SSI index assesses how different the six sampled substrates are in terms of species composition and was calculated as

$S S I=\frac{2 w}{m+n}$,

with $m$ being the total number of species identified in the first substrate, $\mathrm{n}$ the total number in the second substrate and $\mathrm{w}$ the number of species common to both substrates (Southwood and Henderson 2000) ranging between 0 (no similarity) and 1 (maximum similarity). Taking the index values into account, similar substrata where then grouped into broader categories. The Lloyd Index of Patchiness (LIP) was used to determine if there are species specialized to particular substrates. It was computed as

$L I P=\frac{S_{x}^{2}-x}{x^{2}}+1$,

where $S_{x}^{2}$ and $x$ are, respectively, the variance and mean of the number of presences in each substrate type per species. We considered a species to be a specialist if a minimum of $80 \%$ of the species records came from one single substrate type, a percentage which translates to an index value higher than 4. The index was only calculated for species represented by a minimum of six samples (microplots), because the species could be collected from six possible substrata.

\section{Results}

Species inventory and sampling completeness

The 636 sampled microplots yielded a total of 92 bryophyte species and subspecies, namely 58 liverworts and 34 mosses (Supplementary Material, Appendix S2). These taxa represent $26 \%$ of the island's bryoflora, with $41 \%$ of all liverworts being present in the transect against only $16 \%$ of all mosses. None of the four hornwort species referred to Terceira Island (Gabriel et al. 2010) was recorded within the plots.

Sampling completeness based on three different richness estimators is always $>90 \%$, both for all bryophytes (mean of $96 \%$ ) and for each separate division (means of $94 \%$ for liverworts and $98 \%$ for mosses). Accumulation curves for each sampled substrate resulted in completeness values ranging from $73 \%$ (rocks) to $90 \%$ (trees) (Supplementary Material, Appendix S3).

\section{Additive partition of bryophyte diversity}

Hierarchical diversity partitioning revealed, as hypothesized, a statistically significant deviation between observed diversity and random expectations $(\mathrm{p}<0.001$ for all diversity components) (Fig. 1). Differences between elevations were the main contribution to beta diversity comprising the bulk of bryophyte diversity, closely followed by differences between substrates and quadrats. The contribution of the elevation component was always greater than expected by chance while that of the substrate component was always lower. Looking at the two bryophyte divisions, the elevation component weighed more in moss diversity than in liverworts, the opposite being true for the substrate component. Also, alpha diversity, despite its low contribution, was in reality higher than predicted by the null models.
Figure 1. Additive partitioning of bryophyte diversity with comparison between observed and expected contributions of each gamma component, both for all bryophytes taken together and for each division separately ( $p<0.001$ for all diversity components).

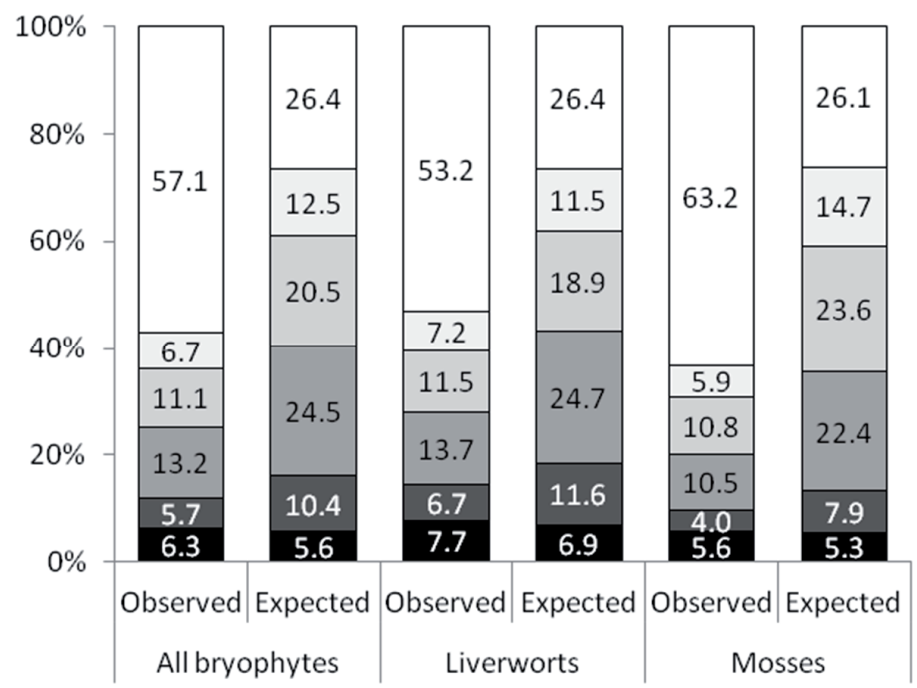

$\square \beta 5$ (between elevations)

$\square \beta 4$ (between plots)

$\square \beta 3$ (between quadrats)

$\square \beta 2$ (between substrates)

$\square \beta 1$ (between microplots)

- $\alpha 1$ (within microplots) 
Partitioning elevation level beta diversity into richness and turnover

Computing overall beta diversity for the main gamma component ( $\beta 5$, between elevational sites) and partitioning it into its richness and replacement elements, we saw that overall beta diversity between adjacent elevational sites decreased almost linearly along the gradient $\left(y=-0.1166 x+0.8908 ; \mathrm{r}^{2}\right.$ $=0.87 ; \mathrm{p}=0.02)$, with bryophyte communities between 600 $\mathrm{m}$ and $1000 \mathrm{~m}$ being the most similar and those between $40 \mathrm{~m}$ and $200 \mathrm{~m}$ being the most different of these five pairs. Species replacement was the main process causing compositional differences between these pairs of adjacent elevation sites and its relative contribution to overall beta diversity increased with elevation from the $200 \mathrm{~m}$ site onward (Fig. 2).

When plotting all possible combinations of pairwise distances between elevations for all bryophytes (Fig. 3), we obtained a classic distance decay in similarity pattern, with

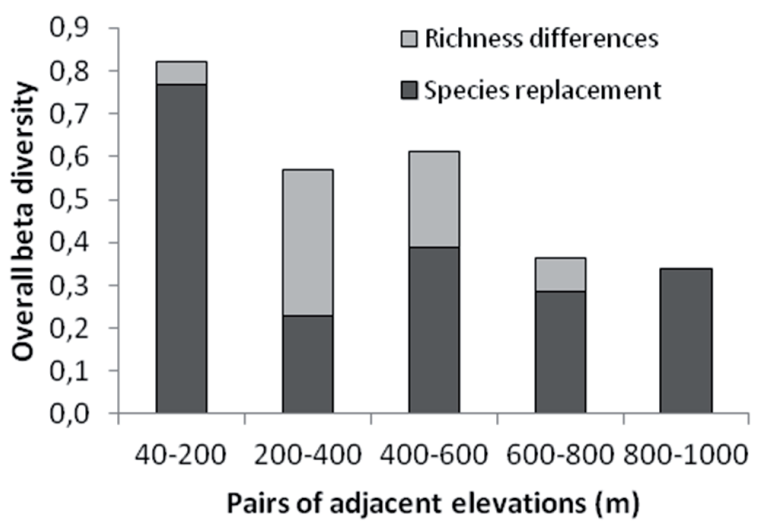

Figure 2. Overall beta diversity divided into its two components, richness differences and species replacement for each pair of adjacent elevational sites along Terceira's gradient.

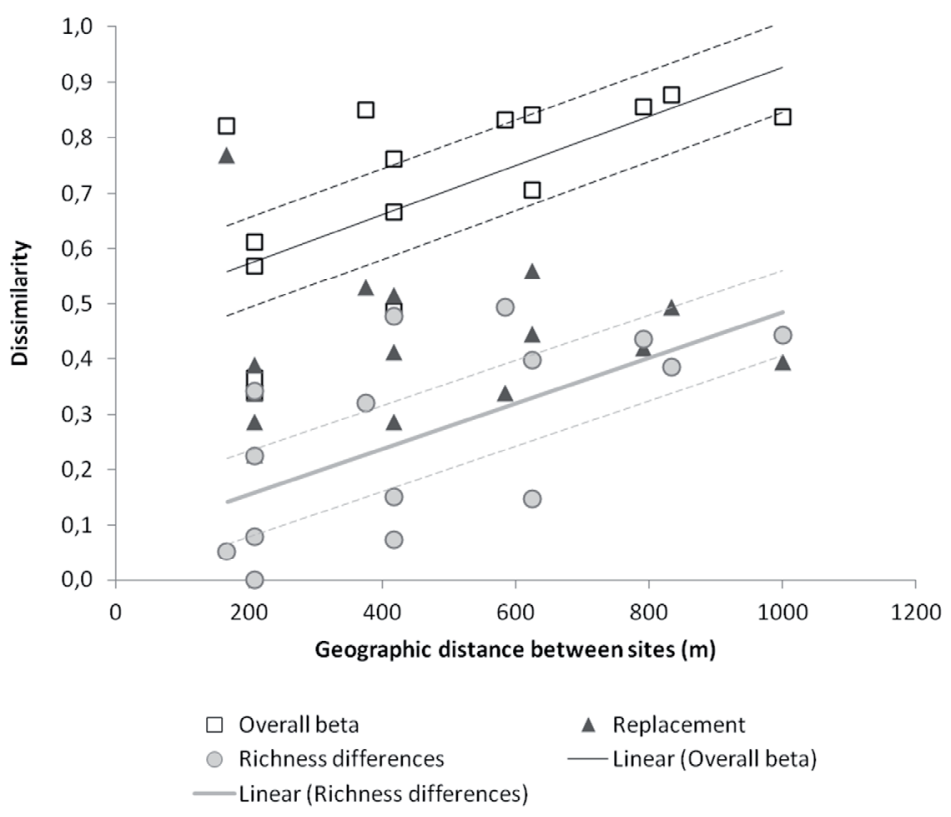

overall beta diversity increasing with distance between elevational sites (Mantel statistic $r=0.63 ; p=0.005$ ), mainly due to richness differences $(r=0.62 ; p=0.036)$. Dissimilarities were smaller between neighboring elevational sites and mostly due to replacement (as seen in Figure 2), but between more distant sites replacement lost significance and the bulk of dissimilarity was due to differences in the number of species present, which increased with elevation (Appendix S1).

\section{Role of environmental variables in elevation level beta diversity}

Mantel tests of the correlation between overall beta diversity and distance matrices for each of the three environmental variables revealed that the minimum relative humidity was the most significant beta diversity driver for all taxonomic groups: bryophytes $(r=0.86 ; p=0.007)$, liverworts $(r=0.84$; $\mathrm{p}=0.007)$ and mosses $(\mathrm{r}=0.83 ; \mathrm{p}=0.017)$. The correlation of overall beta with anthropogenic disturbance was only significant for liverworts $(r=0.58 ; p=0.026)$ and maximum tree height was not significantly correlated with overall beta for any division. Since all significant correlations were positive, this means that elevational sites more dissimilar between them in terms of minimum relative humidity and disturbance are also more distinct in their bryophyte species composition.

\section{Substrate level beta diversity}

At the substrate level, the Sørensen Similarity Index revealed a great resemblance among substrates in terms of species composition. More than three quarters of all pairwise comparisons (78\%) resulted in similarity values above 0.5 . Looking at the two divisions, liverwort composition is always more consistent among substrates than moss composition, except when comparing soil and rocks (Table 1).

Taking these similarities into account, we can broadly categorize the six substrates as ground substrates (humus, soil
Figure 3. Overall beta diversity divided into its two components, richness differences and species replacement (with two data markers obscured by overlap with richness differences at $200 \mathrm{~m}$ distance) for each possible pair of elevational sites along Terceira's gradient, plotted against elevational distance between sites. The calculated significant regression lines (solid lines) and 95\% confidence intervals of the regressions (broken lines) are shown for overall beta and richness differences. 
Table 1. Sørensen Similarity between pairs of substrate types for all bryophytes taken together and for liverworts and mosses separately. The more similar the species composition between a pair of substrata, the closer the index gets to 1.00 .

\begin{tabular}{lccc}
\hline Substrata & All bryophytes & Liverworts & Mosses \\
\hline Humus vs. Soil & 0.80 & 0.81 & 0.78 \\
Humus vs. Rock & 0.60 & 0.66 & 0.51 \\
Humus vs. Decaying wood & 0.74 & 0.83 & 0.59 \\
Humus vs. Trees & 0.68 & 0.69 & 0.65 \\
Humus vs. Leaves & 0.49 & 0.57 & 0.33 \\
Soil vs. Rock & 0.59 & 0.58 & 0.60 \\
Soil vs. Decaying wood & 0.77 & 0.82 & 0.67 \\
Soil vs. Trees & 0.70 & 0.71 & 0.68 \\
Soil vs. Leaves & 0.47 & 0.56 & 0.32 \\
Rock vs. Decaying wood & 0.65 & 0.70 & 0.53 \\
Rock vs. Trees & 0.56 & 0.61 & 0.44 \\
Rock vs. Leaves & 0.36 & 0.43 & 0.21 \\
Decaying wood vs. Trees & 0.79 & 0.80 & 0.76 \\
Decaying wood vs. Leaves & 0.58 & 0.65 & 0.38 \\
Trees vs. Leaves & 0.53 & 0.56 & 0.43 \\
\hline
\end{tabular}

Figure 4. Number of moss and liverwort records in proportion to number of samples for each substrate, namely soil (TE), humus (HU), rocks (RU), decomposing wood (LI), trees (T) and leaves (LF).

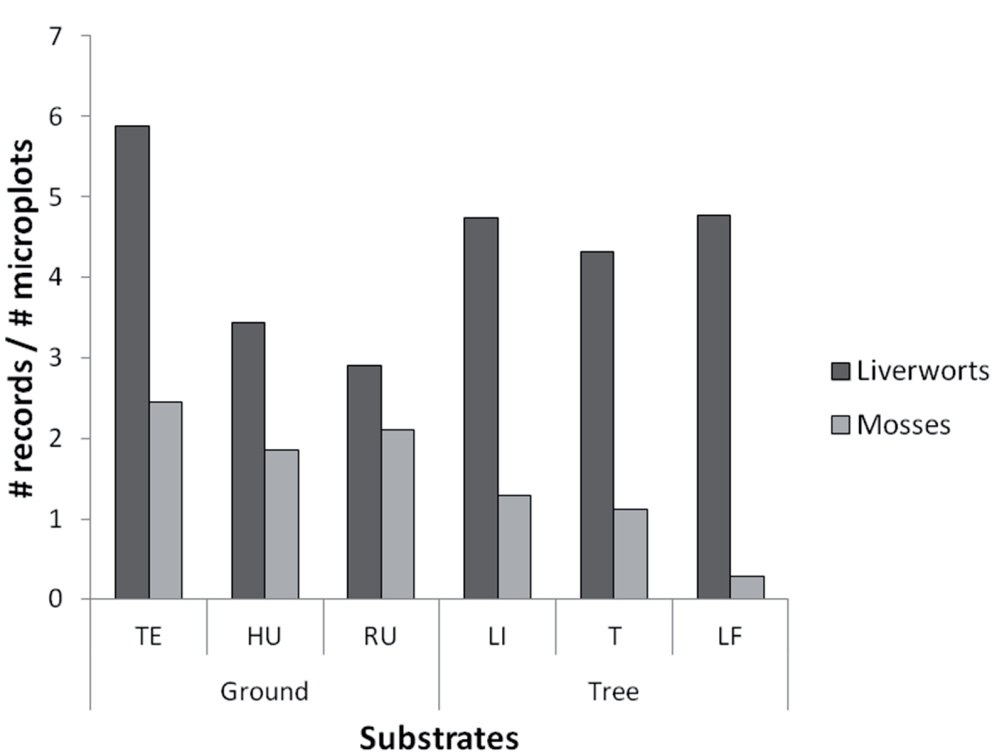

and rocks) and tree substrates (decomposing wood, trees and leaves). Looking, for each substrate, at the number of records in proportion to the number of collected samples (Fig. 4), we can see that terricolous samples yielded more records than any other substrate. Also, the bulk of records correspond to the presence of liverworts, regardless of the substrate. The presence of mosses was more expressive on the ground substrates and less on the tree substrates, being almost immaterial in leaves.

Complementing these findings, Lloyd's index of patchiness (LIP) revealed only nine substrate-specialized species (LIP > 4), five mosses (Fissidens taxifolius, Isothecium prolixum, Myurium hochstetteri, Polytrichastrum formosum and Tortella flavovirens) and four liverworts (Cololejeunea azorica, Fuscocephaloziopsis connivens, Lophocolea heterophylla and Pseudomarsupidium decipiens). Two of these mosses specialize on colonizing rocks ( $F$. taxifolius and $T$. flavovirens) while I. prolixum (a Macaronesian endemic) and $M$. hochstetteri predominate on trees. The moss $P$. formosum and the liverwort $F$. connivens are humiculous specialists and the remaining liverworts appear preferentially as epiphytes.

\section{Discussion}

\section{Species inventory and sampling completeness}

Despite the high sampling completeness values, the alpha component constitutes less than $10 \%$ of total bryophyte diversity for the studied elevational transect, with species inventory only managing to capture $26 \%$ of the island's known taxa. Nonetheless, it is important to point out that sampling efforts were focused only on a western section of the island and in just one habitat category, native vegetation. This is merely one of five main land uses in the island, the others being so- 
cial areas, exotic forests, intensive pastures and semi-natural pastures (Aranda et al. 2010), and though most anthropogenic habitats do not seem to exclusively harbor any bryophyte species, some taxa have only been reported for specific habitats not covered by this sampling protocol, like Riccia ligula in intensive pastures (Gabriel et al. 2011) and several Sphagnum species in peatlands (Bates and Gabriel 1997, Dias et al. 2009). The importance of local richness could thus vary between different land-uses (as reported by Aranda et al., 2010), an hypothesis worth exploring in future studies.

\section{Additive partition of bryophyte diversity}

Beta diversity proved to be the most important element of gamma diversity for the transect's bryoflora, with the broadscale beta component being greater than expected and constituting more than $50 \%$ of total diversity. The substrate and quadrat components, despite contributing less than expected by chance, are the second most important beta elements, making for $13 \%$ and $11 \%$ respectively of gamma (almost $14 \%$ and $12 \%$ for liverworts and $10.5 \%$ and $10,8 \%$ for mosses), suggesting that the large scale effects of elevation and its associated climatic gradients lead the way in structuring the richness and composition of bryophytes in Terceira's natural forest patches, but small scale substrate and quadrat preferences are also important in promoting diversity. In turn, mesoscale sampling levels (plots) explain less variation. Similar results have been reported, namely by Mills and Macdonald (2004), which concluded that microscale variables (substrate type and properties) are more important as bryophyte diversity predictors than mesoscale (plot level) variables in Canadian boreal stands.

Looking at the two bryophyte divisions, moss diversity is the most dependent on elevation differences. This corroborates the findings of previous studies that reported a tendency of some of the island's moss species to be narrow-ranged, especially at low elevations (Henriques et al. 2016). In addition, it also supports the fact that, when examined separately, species turnover proved to be more important for moss assemblages than for liverworts (results not shown), indicating a higher rate of species substitution along the gradient for mosses, mirroring the pattern recently described by Spitale (2016) for the Italian Alps spruce forest bryophytes. As for liverworts, more dependent than mosses on the substrate component, it is worth mentioning that two of the sampled endemics, Bazzania azorica and Telaranea azorica, when present as epiphytes were found exclusively on the endemic phorophyte Juniperus brevifolia, reinforcing the idea that this species is an important substrate to several taxa in the Azores, from arthropods to bryophytes (Nunes et al. 2015).

\section{Partitioning elevation level beta diversity into richness and turnover}

Unsurprisingly, as distance between elevational sites increases, compositional differences also increase, these being mainly due to the increment in bryophyte richness along the transect, reaching its optimum at $600 \mathrm{~m}$ with 54 species and then stabilizing at 49 species in the last two sites (Appendix S1). This distance decay of similarity (Soininen et al. 2007) echoes the decrease in environmental similarity with distance, causing differences in species composition according to their physiological preferences (Nekola and White 1999). In this case, Terceira's bryophyte richness peaks at mid-high elevations due to optimum temperature and humidity conditions, as previously reported (Henriques et al. 2016). However, when restricting our analysis to each pair of adjacent sites, we find that species turnover is the main process at work, indicating a gradual gain and loss of species along the gradient due to environmental filtering, competition and historical events, such as disturbance (Legendre 2014). The importance of this component is highest between the two lowest elevations, the two most disturbed sites, and disturbance is known to have a positive effect on beta diversity by increasing the variability of abundances and changes in species identities (Warwick and Clarke 1993). The importance of richness differences for overall beta increases with distance between sites, accompanying an increase in species numbers along this small elevational gradient.

\section{Role of environmental variables in elevation level beta diversity}

The most significant correlate of bryophyte beta diversity at the regional scale is minimum relative humidity, followed by the disturbance index. In fact, communities of moister sites at mid-high elevation which also occur in less disturbed forest patches harbor a consistently richer bryoflora (Dias et al. 2005), differing also less in terms of bryophyte species composition. As bryophytes are largely ectohydric, lacking typical internal conducting tissues and absorbing water and nutrients over the whole surface of their gametophytes, they favor moistness availability in the atmosphere (Tuba et al. 2011, Song et al. 2015), which can explain this pattern. This correlation is particularly significant for liverworts and not so much for mosses. This is probably due to the fact that most leafy liverworts have lower desiccation tolerances and require damper conditions than mosses, which are better adapted to preserve water (Gabriel 2000, Grau et al. 2007).

\section{Substrate level beta diversity}

At the substrate scale, the low rate of specialization of the transect's bryophytes (nine out of 92 taxa, approximately $10 \%$ ) along with the high similarity values between most substrates (soil and humus, leaves and trees) can explain why the contribution of the substrate component of beta diversity is consistently lower than would be expected by chance. On the whole, the different substrates end up creating some ecological redundancy, with most species being present in multiple substrates and most substrates supporting a wide variety of species, a pattern already reported for the archipelago's bryoflora (Sjögren 2003, Gabriel and Bates 2005). This lack of substratum preference was tentatively explained by Sjögren (2003) as the result of optimal habitat conditions in the Azores, with substrate preferences appearing to be more 
obvious when species occur at the margin of their survival ability (Sjögren 1997, Wagner et al. 2015).

Since biodiversity is an innately spatial concept (Bennie et al. 2011), understanding how it varies with scale is essential to identify what drives it and which spatial extents are more appropriate as the focus of management and conservation efforts intending to maintain it. In this context, our work shows that any attempts to evaluate and/or safeguard bryophyte (and particularly moss) diversity in Terceira can only be valid if including multiple sites within different elevations, from the seashore to the top of the island. These findings add an extra layer to the knowledge of bryophyte diversity patterns in Terceira, providing land-use planners with information that may help structure regional bryophyte conservation strategies. For example, broad scale approaches such as the protection and rehabilitation of additional natural vegetation patches at different elevations (mainly in the lowlands, where native forests are all but gone) will be more effective in adding to and conserving bryophyte diversity than management approaches directed at maintaining and improving bryophyte species richness and abundances within existing sites.

Acknowledgements. We thank Dr. C. Sérgio (LISU, University of Lisbon, Portugal) for helping with the identification of several species and Dr. F. Rigal (Université de Pau et des Pays de l'Adour, France) for assistance with the $\mathrm{R}$ software. The first author is financially supported by Fundo Regional para a Ciência e Tecnologia (FRCT) - Regional Government of the Azores (Ph.D. grant M3.1.2/F/051/2011) and by the ERANET BIOME MOVECLIM "Montane vegetation as listening posts for climate change" (research project M2.1.2/F/04/2011/NET).

\section{References}

Agostinho, J. 1942. Clima dos Açores. Açoreana 3:35-65.

Ah-Peng, C., N. Wilding, J. Kluge, B. Descamps-Julien, J. Bardat, M. Chuah-Petiot, D. Strasberg and T.A.J. Hedderson. 2012. Bryophyte diversity and range size distribution along two altitudinal gradients: Continent vs. island. Acta Oecol. 42:58-65.

Andrew, N.R. and L. Rodgerson. 2003. Variation in invertebrate bryophyte community structure at different spatial scales along altitudinal gradients. J. Biogeogr. 30:731-746.

Aranda, S.C. 2013. Bryophyte diversity patterns in the Macaronesian region. Ph.D. thesis, Universidad de Alcalá, Madrid, Spain.

Aranda, S.C., R. Gabriel, P.A.V. Borges and J.M. Lobo. 2010. Assessing the completeness of bryophyte inventories: an oceanic island as a case study (Terceira, Azorean archipelago). Biodivers. Conserv. 19:2469-2484.

Aranda, S.C., R. Gabriel, P.A.V. Borges, A.M.C. Santos, E.B. Azevedo, J. Patiño, J. Hortal and J.M. Lobo. 2014. Geographical, temporal and environmental determinants of bryophyte species richness in the Macaronesian Islands. PLoS ONE 9:e101786.

Azevedo, E.B., L. Santos Pereira and B. Itier. 1999. Modelling the local climate in island environments: water balance applications. Agric. Water Manage. 40:393-403.

Bates, J.W. and R. Gabriel. 1997. Sphagnum cuspidatum and S. imbricatum ssp. affine new to Macaronesia, and other new island records for Terceira, Azores. J. Bryol. 19:645-648.
Bennie, J., K. Anderson and A. Wetherelt. 2011. Measuring biodiversity across spatial scales in a raised bog using a novel pairedsample diversity index. J. Ecol. 99:482-490.

Cardoso, P., F. Rigal, S. Fattorini, S. Terzopoulou and P.A.V. Borges. 2013. Integrating landscape disturbance and indicator species in conservation studies. PLOS ONE 8:e63294.

Carvalho, J.C., P. Cardoso and P. Gomes. 2012. Determining the relative roles of species replacement and species richness differences in generating beta-diversity patterns. Global Ecol. Biogeogr. 21:760-771.

Caujapé-Castells, J., A. Tye, D.J. Crawford, A. Santos-Guerra, A. Sakai, K. Beaver, W. Lobin, F.B. Vincent Florens, M. Moura and R. Jardim. 2010. Conservation of oceanic island floras: Present and future global challenges. Persp. Plant Ecol. Evol. Syst. 12:107-129.

Courchamp, F., B.D. Hoffmann, J.C. Russell, C. Leclerc and C. Bellard. 2014. Climate change, sea-level rise, and conservation: Keeping island biodiversity afloat. Trends Ecol. Evol. 29:127130.

Dias, E. and C. Mendes. 2007. Characterisation of a basin mire in the Azores archipelago. Mires and Peat 2:1-11.

Dias, E., C. Mendes, C. Melo, D. Pereira and R.B. Elias. 2005. Azores central islands vegetation and flora-field guide. Quercetea 7:123-173.

Dias, E., C. Mendes and J. Shaw. 2009. Sphagnum recurvum P. Beauv. on Terceira, Azores, new to Macaronesia-Europe. J. Bryol. 31:199-201.

Ellis, L.T., M. Aleffi, V.A. Bakalin, H. Bednarek-Ochyra, A. Bergamini, P. Beveridge, S.S. Choi, V. Fedosov, R. Gabriel, M.T. Gallego, S. Grdović, R. Gupta, V. Nath, A.K. Asthana, L. Jennings, H. Kürschner, M. Lebouvier, M.C. Nair, K.M. Manjula, K.P. Rajesh, M. Nobis, A. Nowak, S.J. Park, B-Y. Sun, V. Plášek, L. Č́íhal, S. Poponessi, M.G. Mariotti, A. Sabovljević, M.S. Sabovljević, J. Sawicki, N. Schnyder, R. Schumacker, M. Sim-Sim, D.K. Singh, D. Singh, S. Majumdar, S. Singh Deo, S. Ştefănuț, M. Suleiman, C.M. Seng, M.S. Chua, J. Ván̆a, R. Venanzoni, E. Bricchi and M J. Wigginton. 2015. New national and regional bryophyte records, 42. J. Bryol. 37:68-85.

Forjaz, V.H. 2004. Atlas básico dos Açores. OVGA, Ponta Delgada, Portugal.

Gabriel, R. 2000. Ecophysiology of Azorean forest bryophytes. Ph.D. thesis, University of London, London, UK.

Gabriel, R. and J.W. Bates. 2005. Bryophyte community composition and habitat specificity in the natural forests of Terceira, Azores. Plant Ecol. 177:125-144.

Gabriel, R., M.C.M. Coelho, D.S.G. Henriques, P.A.V. Borges, R.B. Elias, J. Kluge and C. Ah-Peng. 2014. Long-term monitoring across elevational gradients to assess ecological hypothesis: a description of standardized sampling methods in oceanic islands and first results. Arquipélago. Life and Marine Sci. 31:45-67.

Gabriel, R., N. Homem, A.B. Couto, S.C. Aranda and P.A.V. Borges. 2011. Azorean bryophytes: a preliminary review of rarity patterns. Açoreana 144:149-206.

Gabriel, R., E. Sjögren, R. Schumacker, C. Sérgio, S.C. Aranda, D. Claro, N. Homem and B. Martins. 2010. Lista de Briófitos (Anthocerotophyta, Marchantiophyta, Bryophyta). In: Listagem dos organismos terrestres e marinhos dos Açores. Principia, Cascais, Portugal. pp. 99-115.

Gering, J.C. and T.O. Crist. 2002. The alpha-beta-regional relationship: providing new insights into local-regional patterns of species richness and scale dependence of diversity components. Ecol. Lett. 5:433-444. 
Gering, J.C., T.O. Crist and J.A. Veech. 2003. Additive partitioning of species diversity across multiple spatial scales: Implications for regional conservation of biodiversity. Conserv. Biol. 17:488499.

Grau, O., J.-A. Grytnes and H.J.B. Birks. 2007. A comparison of altitudinal species richness patterns of bryophytes with other plant groups in Nepal, Central Himalaya. J. Biogeogr. 34:1907-1915.

Henriques, D.S.G., P.A.V. Borges, C. Ah-Peng and R. Gabriel. 2016. Mosses and liverworts show contrasting elevational distribution patterns in an oceanic island (Terceira, Azores): the influence of climate and space. J. Bryol. 38:183-194.

Hortal, J., P.A.V. Borges and C. Gaspar. 2006. Evaluating the performance of species richness estimators: Sensitivity to sample grain size. J. Animal Ecol. 75:274-287.

Jost, L. 2010. Independence of alpha and beta diversities. Ecology 91:1969-1974.

Jost, L., P. DeVries, T. Walla, H. Greeney, A. Chao and C. Ricotta. 2010. Partitioning diversity for conservation analyses. Divers. Distrib. 16:65-76.

Kreft, H., W. Jetz, J. Mutke, G. Kier and W. Barthlott. 2008. Global diversity of island floras from a macroecological perspective. Ecol. Lett. 11:116-27.

Lande, R. 1996. Statistics and partitioning of species diversity, and similarity among multiple communities. Oikos 76:5-13.

Legendre, P. 2014. Interpreting the replacement and richness difference components of beta diversity. Global Ecol. Biogeogr. 23:1324-1334.

Legendre, P. and L. Legendre. 1998. Numerical Ecology. Elsevier, Amsterdam.

Lloyd, M. 1967. Mean crowding. J. Animal Ecol. 36:1-30.

Miller, H. and H. Whittier. 1990. Bryophyte floras of tropical Pacific islands. Trop. Bryol. 2:167-175.

Mills, S.E., and S.E. Macdonald. 2004. Predictors of moss and liverwort species diversity of microsites in conifer-dominated boreal forest. J. Veg. Sci. 15:189-198.

Müller, J. and M.M. Goßner. 2010. Three-dimensional partitioning of diversity informs state-wide strategies for the conservation of saproxylic beetles. Biol. Conserv. 143:625-633.

Nekola, J.C., and P.S. White. 1999. The distance decay of similarity in biogeography and ecology. J. Biogeogr. 26:867-878.

Nunes, R., R. Gabriel, R.B. Elias, F. Rigal, A.O. Soares, P. Cardoso and P.A.V. Borges. 2015. Arthropods and other biota associated with the Azorean trees and shrubs: Juniperus brevifolia. Arquipélago. Life and Marine Sci. 32:19-48.

Paulay, G. 1994. Biodiversity on oceanic islands: Its origin and extinction. Integr. Compar. Biol. 34:134-144.

Ricotta, C. 2005. On hierarchical diversity decomposition. J. Veg. Sci. 16:223-226

Ros, R.M., V. Mazimpaka, U. Abou-Salama, M. Aleffi, T.L. Blockeel, M. Brugués, R.M. Cros, M.G. Dia, G.M. Dirkse, I. Draper, W. El-Saadawi, A. Erdağ, A. Ganeva, R. Gabriel, J.M. GonzálezMancebo, C. Granger, I. Herrnstadt, V. Hugonnot, K. Khalil, H. Kürschner, A. Losada-Lima, L. Luís, S. Mifsud, M. Privitera, M. Puglisi, M. Sabovljević, C. Sérgio, H.M. Shabbara, M. SimSim, A. Sotiaux, R. Tacchi, A. Vanderpoorten and O. Werner. 2013. Mosses of the mediterranean, an annotated checklist. Cryptogamie, Bryologie 34:99-283.

Silveira, L.M.A. 2013. Aprender com a História: Modos de Interacção cpm a Natureza na Ilha Terceira (Do Povoamento ao seculo $X X)$. Principia, Cascais, Portugal.
Sjögren, E. 2003. Azorean bryophyte communities - a revision of differential species. Arquipélago. Life and Marine Sci. 20:1-29.

Sjögren, E. 1997. Epiphyllous bryophytes in the Azores Islands. Arquipélago. Life and Marine Sci. 15:1-49.

Söderström, L., A. Hagborg, M. Von Konrat, S. Bartholomew-Began, D. Bell, L. Briscoe, E. Brown, D.C. Cargill, D.P. da Costa, B.J. Crandall-Stotler, E.D. Cooper, G. Dauphin, J.J. Engel, K. Feldberg, D. Glenny, S.R. Gradstein, X. He, J. Heinrichs, J. Hentschel, A.L. Ilkiu-Borges, T. Katagiri, N.A. Konstantinova, J. Larraín, D.G. Long, M. Nebel, T. Pócs, F. Puche, E. ReinerDrehwald, M.A. Renner, A. Sass-Gyarmati, A. SchäferVerwimp, J.G. Moragues, R. Stotler, P. Sukkharak, B.M. Thiers, J. Uribe, J. Váňa, J.C. Villarreal, M. Wigginton, L. Zhang and R.L. Zhu. 2016. World checklist of hornworts and liverworts. PhytoKeys 59:1-828.

Soininen, J., R. McDonald and H. Hillebrand. 2007. The distance decay of similarity in ecological communities. Ecography 30:3-12.

Song, L., W.-Z. Ma, Y.-L. Yao, W.-Y. Liu, S. Li, K. Chen, H.-Z. Lu, M. Cao, Z.-H. Sun, Z.-H. Tan and A. Nakamura. 2015. Bole bryophyte diversity and distribution patterns along three altitudinal gradients in Yunnan, China. J. Veg. Sci. 26:576-587.

Southwood, T.R.E. and P.A. Henderson. 2000. Ecological Methods. Blackwell Science Ltd, London, UK.

Spitale, D. 2016. The interaction between elevational gradient and substratum reveals how bryophytes respond to the climate. $J$. Veg. Sci. 27:844-853.

Suren, A.M. 1996. Bryophyte distribution patterns in relation to macro, meso, and micro-scale variables in South Island, New Zealand streams. New Zealand Journal of Marine and Freshwater Research 30:501-523.

Sutherland, W.J., R.P. Freckleton, H.C.J. Godfray, S.R. Beissinger, T. Benton, D.D. Cameron, Y. Carmel, D.A. Coomes, T. Coulson, M.C. Emmerson, R.S. Hails, G.C. Hays, D.J. Hodgson, M.J. Hutchings, D. Johnson, J.P.G. Jones, M.J. Keeling, H. Kokko, W.E. Kunin, X. Lambin, O.T. Lewis, Y. Malhi, N. Mieszkowska, E.J. Milner-Gulland, K. Norris, A.B. Phillimore, D.W. Purves, J.M. Reid, D.C. Reuman, K. Thompson, J.M.J. Travis, L.A. Turnbull, D.A. Wardle and T. Wiegand. 2013. Identification of 100 fundamental ecological questions (D. Gibson, Ed.). J. Ecol. 101:58-67.

Tuba, Z., N.G. Slack and L.R. Stark. 2011. Bryophyte Ecology and Climate Change. Cambridge University Press, Cambridge, UK.

Veech, J.A. and T.O. Crist. 2010. Diversity partitioning without statistical independence of alpha and beta. Ecology 91:1964-1969.

Veech, J.A., K.S. Summerville, T.O. Crist and J.C. Gering. 2002. The additive partitioning of species diversity: recent revival of an old idea. Oikos 99:3-9.

Wagner, K., G. Mendieta-Leiva and G. Zotz. 2015. Host specificity in vascular epiphytes: a review of methodology, empirical evidence and potential mechanisms. AoB PLANTS 7: plu092-plu092.

Warren, B.H., D. Simberloff, R.E. Ricklefs, R. Aguilée, F.L. Condamine, D. Gravel, H. Morlon, N. Mouquet, J. Rosindell, J. Casquet, E. Conti, J. Cornuault, J.M. Fernández-Palacios, T. Hengl, S.J. Norder, K.F. Rijsdijk, I. Sanmartín, D. Strasberg, K.A. Triantis, L.M. Valente, R.J. Whittaker, R.G. Gillespie, B.C. Emerson, C. Thébaud. 2015. Islands as model systems in ecology and evolution: Prospects fifty years after MacArthur-Wilson. Ecol. Lett. 18:200-217.

Warwick, R.M. and K.R. Clarke. 1993. Increased variability as a symptom of stress in marine communities. J. Exp. Marine Biol. Ecol. 172:215-226.

Whittaker, R.J. 1960. Vegetation of the Siskiyou Mountains, Oregon and California. Ecol. Monogr. 30:279-338. 
Whittaker, R.J., K.J. Willis and R. Field. 2001. Scale and species richness: towards a general, hierarchical theory of species diversity. J. Biogeogr. 28:453-470.

Wiens, J.A. 1989. Spatial scaling in ecology. Funct. Ecol. 3:385-397.

Williams, S.E., H. Marsh and J. Winter. 2002. Spatial scale, species diversity, and habitat structure: small mammals in Australian tropical rain forest. Ecology 83:1317-1329.

Received June 22, 2017

Revised September 21, October 25, 2017 Accepted November 11, 2017

Open Access. This article is distributed under the terms of the Creative Commons Attribution 4.0 International License (https://creativecommons.org/licenses/by/4.0/), which permits unrestricted use, distribution, and reproduction in any medium, provided the original author and source are credited, you give a link to the Creative Commons License, and indicate if changes were made.

\section{Supplemetary Material}

Appendix S1. Values of climatic, landscape and biological variables for each elevational site of Terceira's transect.

Appendix S2. List of liverwort and moss taxa identified in Terceira's elevational gradient.

Appendix S3. Observed and estimated bryophyte richness (with Jacknife 1, Jacknife 2 and Chao 2) and inventory completeness percentage for Terceira's gradient.

The file may be downloaded from www.akademai.com. 